\title{
Optimizing Geothermal Energy Resource
}

\author{
Mohamad Kharseh and Mohammed Al-Khawaja \\ Mechanical \& Industrial Engineering Department, Qatar University, Doha 2713, Qatar
}

\begin{abstract}
Unlike other types of renewable energy resources, geothermal energy provides a stable source of energy as it can be exploited regardless of meteorological conditions. Using organic cycle, geothermal energy can be utilized for power generation. In such systems, the heat is exchanged between the surrounding rock mass and transport fluid. Consequently, the temperature of extracted geofluid from the well decreases with the time in accordance with the working parameters. Those parameters includeenergy extraction rate, temperature difference between inlet and outlet of the well, and the thermal conductivity of the ground. Current work, aims to develop a reliable computer model to specify the optimal working parameters so that the geofluid temperature will not reach a low value that is not acceptable for electricity generation, and the energy availability of geothermal resource is maximized. In the current study the ground thermal properties, the geothermal gradient and well dimensions are based on realistic data in Qatar and neighboring countries. The proposed model was developed for different heat extraction rate, different ground thermal properties, and for varied temperature difference between inlet and outlet of the well. Simulation shows that selecting the optimal working parameters can increase the availability of geothermal resource significantly.
\end{abstract}

Key words: Geothermal resource, heat transfer, optimizing, computer simulation, exergy.

\section{Introduction}

Geothermal energy is a renewable energy source that is showing considerable potential due to the low impact on the environment, very low greenhouse gas emissions, and its ability to be extracted from all over the globe. Furthermore, geothermal energy provides a stable source of energy as it can be exploited regardless of meteorological conditions, while alternative types of renewable energies are dependent upon meteorological conditions and supply intermittent energy (e.g. solar, wind, tidal, etc.). Presently, the global installed geothermal energy production capacity has increased from 1,300 MWe in 1975 to 10,715 MWe in 2010 [1].

Geothermal energy can be harnessed to provide thermal energy for direct use applications (e.g. agricultural drying, zinc and gold ore recovery, etc.), to supply space heating and cooling, and to generate electricity. Space heating and cooling can utilize geothermal energy directly (e.g. greenhouse heating [2]), or indirectly through the use of a heat pump (e.g.

Corresponding author: Mohamad Kharseh, Ph.D., research fields: heat transfer and thermodynamic. melting snow/ice from bridges and roads [3]). Additionally, space heating/cooling can be supplied by a horizontally oriented geothermal heat exchanger (e.g. Esen et al. [4]) so as to further eliminate the high costs associated with drilling a borehole. Power generation with a binary cycle requires an outlet temperature of at least $74{ }^{\circ} \mathrm{C}$ [5], while other methods require significantly hotter outlet temperatures.

When petroleum reservoirs are depleted beyond an economically feasible point, the wells are abandoned, decommissioned, and reclaimed. Petroleum wells that access a reservoir containing an economically unfeasible type or amount of petroleum are also abandoned, and are referred to as "dry" wells. Abandoned petroleum wells are an enduring liability to the companies that drill them, as the specific company is responsible for the possible environmental contamination and litigation in the case of a failed decommissioning of a well.

Abandoned petroleum wells present an interesting opportunity to be retrofitted as a geothermal system as they are generally deep enough to access higher temperature strata of the earth. The depth of 
exploratory and production wells for crude oil and natural gas (including dry holes) drilled in the US during the period from 1949-2008, vary from 945 meters up to 2,560 meters in depth [6]. This range of well depths is a good indicator of petroleum well depths worldwide as the US has sunk over 2.5 million petroleum wells since the 1950's and is the country with the highest rate of oil and gas drilling in the world [7].

Repurposing abandoned petroleum well for a geothermal project can reduce the capital costs of the project by up to $50 \%[1,8]$, as well as making a constructive use for an enduring liability. The capital costs for a geothermal project can be further diminished by employing a closed loop configuration (i.e. closed circuit of pipes), as it can be retrofitted to a single borehole. Alternatively, an open loop configuration requires at least two boreholes to operate, namely an injection well and an extraction well. Additionally, a closed loop system does not require a water management system, compared to a compulsory water management system for open loop configurations. Closed loop configurations will also necessitate a lower pumping power compared to an open loop configuration, due to the thermosiphon effect present in the closed system. Moreover, closed loop configurations have the advantageous option of using a non-aqueous fluid with a lower boiling point than water to increase the heat exchange with the earth.

Another important aspect of retrofitting abandoned wells is the availability of large amounts of thermophysical data that are logged and available on existing wells. These data can be used to ascertain which wells will provide the highest bottom temperature and which are in proximity to the demand for energy. Likewise, the data can also be used to define resources and conditions pertinent to designing a closed loop geothermal heat exchanger. Abandoned wells can even be redrilled, in order to access superior conditions and resources, at a lower cost than drilling a new well.
The majority of work that has been done on retrofitting abandoned petroleum wells as a source for geothermal energy has been focused on open loop systems that repurpose the petroleum reservoir as a geothermal reservoir. There are a multitude of countries that have sponsored research and/or work specific to adapting an open loop design to abandoned wells, including: Albania [9], China [10], Croatia [11], Hungary [12], New Zealand [13], Poland [14], and the US [15]. Further work has been carried out by Sanyal and Butler [16] on the effects of different parameters on the extraction of geothermal energy using an open loop system.

U-tube and double pipe heat exchangers are the focus of the researches that have been accomplished on closed loop systems retrofitted to abandoned petroleum wells. One of those papers proposed a numerical solution to determine the performance of a U-tube heat exchanger in an abandoned well, and it refers to the need to take into account the convective heat flow through the porous medium surrounding the borehole [7]. The few available papers, on the design and performance of a double pipe system retrofitted to an abandoned well, include: Davis and Michaelides [17], $\mathrm{Bu}$ et al. [1], and Kujawa et al. [18]. Alternatively, there are many papers about the design of U-tube and double pip heat exchangers with new geothermal wells (e.g. Al-Khoury \& Bonnier [19], Wang et al. [20], Garbai \& Méhes [21], Zhongjian \& Zheng [22]).

Kujawa et al. [18] examined the feasibility of retrofitting an existing deep production well with a closed loop double pipe heat exchanger to harness the geothermal energy. The paper concludes that the flow rate, inlet fluid temperature, and insulation on the inner pipe have a significant influence on the performance of the heat exchanger. The model proposed by Kujawa et al. [18] simplifies the heat flow surrounding the borehole, by modeling a time dependent radius beyond which the influence of geothermal energy extraction is inconsequential. This assumption is an empirical simplification, which describes the heat transfer in the 
ground surrounding the borehole. Davis and Michaelides [17] proposed a model to explore the feasibility of power production using geothermal power obtained from an abandoned oil well. Their double pipe heat exchanger uses an organic fluid in lieu of water. The simulations consider the effects of the temperature of the well, injection pressure, and flow rate of the organic working fluid. Davis and Michaelides' [17] model assumes that the ground temperature is not transient which therefore results in an overestimation of the power production capacity. The model proposed by $\mathrm{Bu}$ et al. [1] examines the potential effects of the working fluid's flow rate and the geothermal gradient on the heat extraction and potential power generation of a double pipe heat exchanger (closed loop) retrofitted to an abandoned petroleum well. Both Davis and Michaelides [17] and $\mathrm{Bu}$ et al. [1] simplified the convective heat transfer coefficient by employing the Dittus-Boelter correlation [23]. The Dittus-Boelter relation was designed for smooth isothermal tubes (i.e. exhibiting constant heat flux through the tube walls), and loses accuracy when there is a large temperature difference. The Dittus-Boelter correlation is inapplicable to scenarios where the temperature of the tube wall is transient due to the simplifications assumed in the derivation of the correlation. Moreover, the Dittus-Boelter correlation was not designed to be applied to heat transfer through an annulus, so there will be inherent uncertainty in the results obtained by Davis and Michaelides [17] and $\mathrm{Bu}$ et al. [1].

Double pipe heat exchangers boast the advantages of having a higher surface area to exchange heat and containing a higher volume of fluid through which to exchange heat, over U-tube heat exchangers. Retrofitting a double pipe heat exchanger to an abandoned well will also require less pumping energy and significantly less grout compared to adapting a u-tube heat exchanger to an abandoned well. The double pipe design with larger cross sectional area indicates that for an identical flow rate, the fluid velocity will be lower compared to a U-tube design. A lower fluid velocity requires less hydraulic pressure to circulate the fluid, resulting in a lower amount of pumping energy. The double pipe design requires enough grout to seal the bottom of the well, whereas the U-tube design necessitates a large volume of grout to facilitate the heat transfer from the surrounding rock mass.

Current work, therefore, aims to develop a reliable computer model to specify the optimal working parameters so that the energy availability from petroleum well is maximized during the expected lifetime of the project. Assumptions made in the current study (such as the ground thermal properties, the geothermal gradient, and the well dimensions) are based on realistic data in Qatar and neighboring region. The proposed model is developed for different heat extraction rate and for temperature difference between inlet and outlet of the well as well as for different ground thermal properties.

\section{Methodology}

Determination of the optimal working parameters, which assure the maximum exergy extracted from a petroleum well, means to specify the optimal extraction rate at a given resource temperature. A computational model was built in order to simulate the heat extraction process in geothermal well. In Qatar, high-temperature wells have been successfully drilled into reservoirs where temperatures exceed $149^{\circ} \mathrm{C}$ [24]. To be more conservative, the source temperature will be taken as $120{ }^{\circ} \mathrm{C}[8,25]$. In other words, the well depth will be selected according to the thermal conductivity so that the initial bottom temperature is $120{ }^{\circ} \mathrm{C}$. Therefore, in order to cover all possible working parameters in the region, the thermal conductivity was assumed to vary between 2 to 3.5 $\mathrm{W} / \mathrm{m} . \mathrm{K}$ and, consequently, the well depth was calculated and found to be between 4 and $7 \mathrm{~km}$. The sink temperature was assumed to be $29{ }^{\circ} \mathrm{C}$, which is equal to the annual mean air temperature. From the 
thermodynamic point of view the optimal working parameters (including the geofluid mass flow rate and heat extraction rate) that maximize the energy availability (exergy) of geothermal resource, is determined.

\subsection{Theoretical Model Description}

The current model considers a closed loop heat exchanger based on a U-tube pipe arrangement. The configuration of the $\mathrm{U}$-tube is that the water is pumped downwards through the one leg and returned to surface through another leg of the pipe.

Assuming that the heat transfer through the rock mass to the heat exchanger is controlled by conduction, Fourier's three dimensional diffusion law can be used to describe the heat conduction throughout the model. In an infinite homogeneous underground and temperature independent soil properties of thermal diffusivity $\alpha$, the temperature of borehole heat exchanger is given in Refs. [26, 27]:

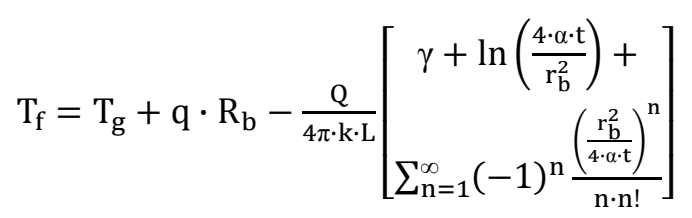

where, $\mathrm{Q}$ is heat extraction rate (W), $\mathrm{k}$ is the thermal conductivity, and $\mathrm{T}_{\mathrm{g}}$ is undisturbed ground initial temperature $\left({ }^{\circ} \mathrm{C}\right), r_{b}$ is the radius of the well $(\mathrm{m}), \alpha$ is thermal diffusivity of the ground $\left(\mathrm{m}^{2} / \mathrm{s}\right), \mathrm{R}_{\mathrm{b}}$ is thermal resistance of the well. Here, $R_{b}$ depends on the tube arrangements inside the well (i.e. single or double U-tube), flow manner inside the tube, and the material of the tube. From the equation, one can notice the temperature of extracted geofluid varies with the time and depends on the working parameters including extraction rate, depth of the well, thermal conductivity and diffusivity of the ground. Thus, to design a closed geothermal system, it is highly important to be able to predict the temperature of the fluid extracted from the well. This will guarantee that the geofluid temperature will not reach a low value that is not acceptable for electricity generation. However, Eq. (1) is the solution of pure heat conduction equation, which does not account for the groundwater movement, and only for a true line source (which does not closely approximate the actual geometry of the borehole). Also Eq. (1) is only valid for time of operation $t>20 \mathrm{r}^{2} / \alpha$. Thus, for a wider range of interest, EED (earth energy designer) is used to determine the temperature of extracted geofluid.

\subsection{Computing Model Description}

The properties of the heat exchanger and surrounding rock mass together with Eq. (1) can be modeled with the commercial modeling software, EED. EED is capable of defining unique properties for each material, so that every component of the model has a specific value for the density, specific heat, thermal conductivity, and velocity. After specifying the extraction rate and the geofluid flow rate, EED computes the geofluid outlet temperature. The resulting outlet temperature is used as an input for EES (engineering equation solver) model developed in the current study. The EES-base model is developed to determine the energy availability of the geofluid based on the extracted geofluid temperature and ambient temperature. As shown in Fig. 1, a calculation loop is created between the EED and EES model to maximize the energy availability of geofluid by determine the optimal extraction energy rate and geofluid flow arte.

\section{Results and Discussions}

The EED base model was used to simulate and determine the geofluid outlet temperature at the mouth of oil well for different extraction rate, different $\Delta \mathrm{T}$ between inlet and outlet of the well, different ground thermal conductivity, and different well depth. Fig. 2 demonstrates the effect of the thermal conductivity, extraction rate and $\Delta \mathrm{T}$ on the outlet fluid temperature. As expected, the calculations show that, for a specific $\Delta \mathrm{T}$, the more the extraction rate the more temperature degradation of geofluid will be. This is due the fact that thermal diffusivity of the rock mass is quite low. 


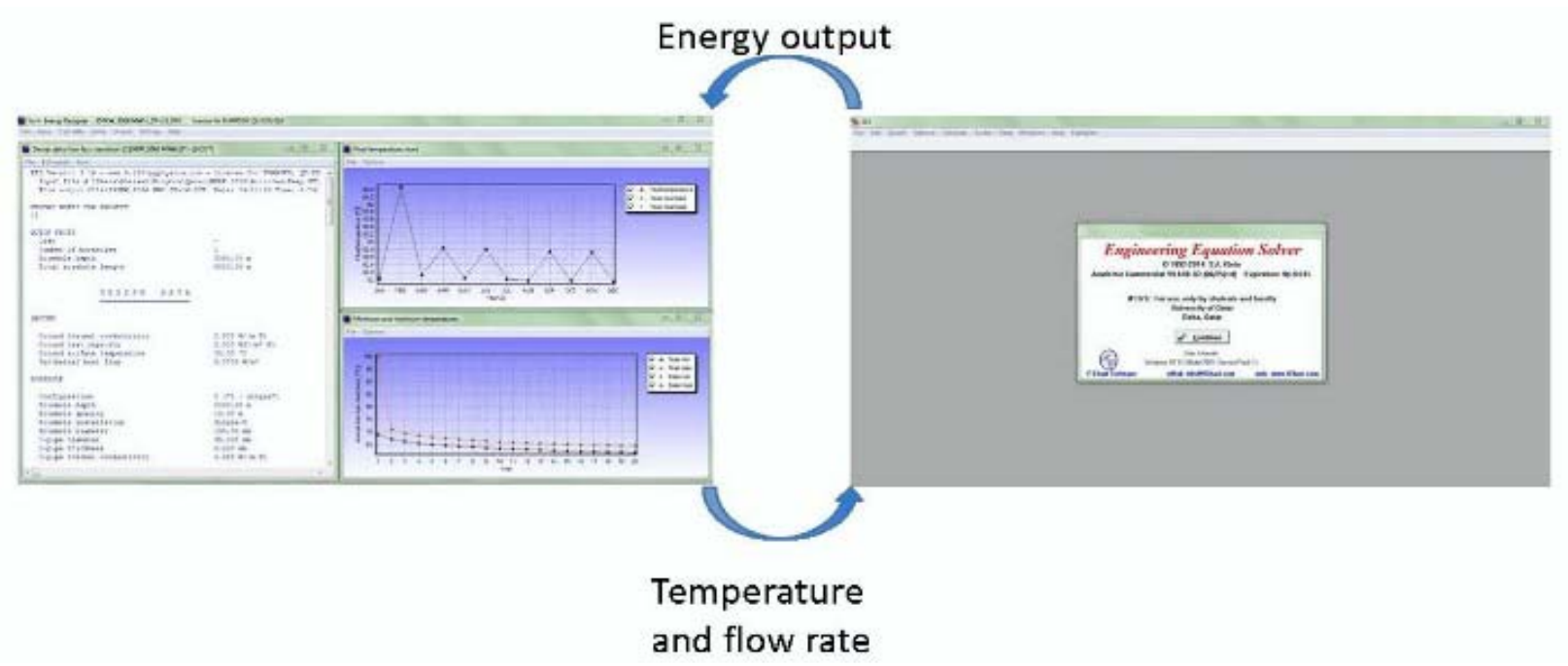

Fig. 1 The combination between EES and EED base models to optimize the energy availability.

Therefore, there will not be enough time to compensate for the extracted heat. In addition, one can see that the thermal conductivity of the ground plays an important role, as it will influence the rate of heat recovery of the geothermal resource. Consequently, a higher thermal conductivity results in a higher geofluid temperature. The thermal conductivity varies for sedimentary rocks from one place to another. Thus, in current study, a range between 2 to $3.5 \mathrm{~W} / \mathrm{m} . \mathrm{K}$ is used as the base value. Also, it should be noted that the temperature difference $\Delta \mathrm{T}$ does not have a significant impact on the extracted geofluid temperature. This can be envisioned from the following: For a given extraction rate, a higher $\Delta \mathrm{T}$ means less flow rate, i.e. slower fluid movement inside the pipe. The slower moving fluid the less heat transfer coefficient will be between the geofluid in the pipe and the surrounding, but also renders longer time for exchanging the heat between the fluid and the surrounding. Consequently, changing temperature difference does not have a significant impact on the outlet temperature of the well, because the reduction in heating coefficient negates the increase in time.

The resulting geofluid temperatures from EED model are introduced as input to the EES model which was built to determine the energy availability (exergy) of geothermal resource. Fig. 3 shows, the higher the thermal conductivity the more energy availability will be. Unlike Fig. 2, the temperature difference $\Delta \mathrm{T}$ has a significant impact on the energy availability of geothermal resource. Smaller temperature difference, higher energy availability can be obtained. Indeed, small $\Delta \mathrm{T}$ leads to higher flow rate without affecting the outlet temperature of the geothermal resource (as discussed before). Consequently, the higher flow rate the more energy availability will be.

The optimal extraction rate and temperature difference $\Delta \mathrm{T}$ strongly depend on the ground properties (i.e. the thermal conductivity and the depth of borehole). For instance, the optimal working condition in a region where the thermal conductivity is 2.5 $\mathrm{W} / \mathrm{m} . \mathrm{K}$ occurs when the extraction rate is $250 \mathrm{~W}$ and the temperature difference $\Delta \mathrm{T}$ is $10{ }^{\circ} \mathrm{C}$. Fig. 4 shows the optimal working parameters for different thermal conductivity.

\section{Conclusions}

An efficient and reliable model, for optimizing the energy availability of geothermal resource, has been demonstrated. The proposed model is used to investigate the effects of some operation parameters (i.e. the flow rate of geofluid, thermal conductivity of the ground, and temperature difference) on the energy availability of geothermal resource. This will guarantee that the geofluid temperature will not reach a low value 

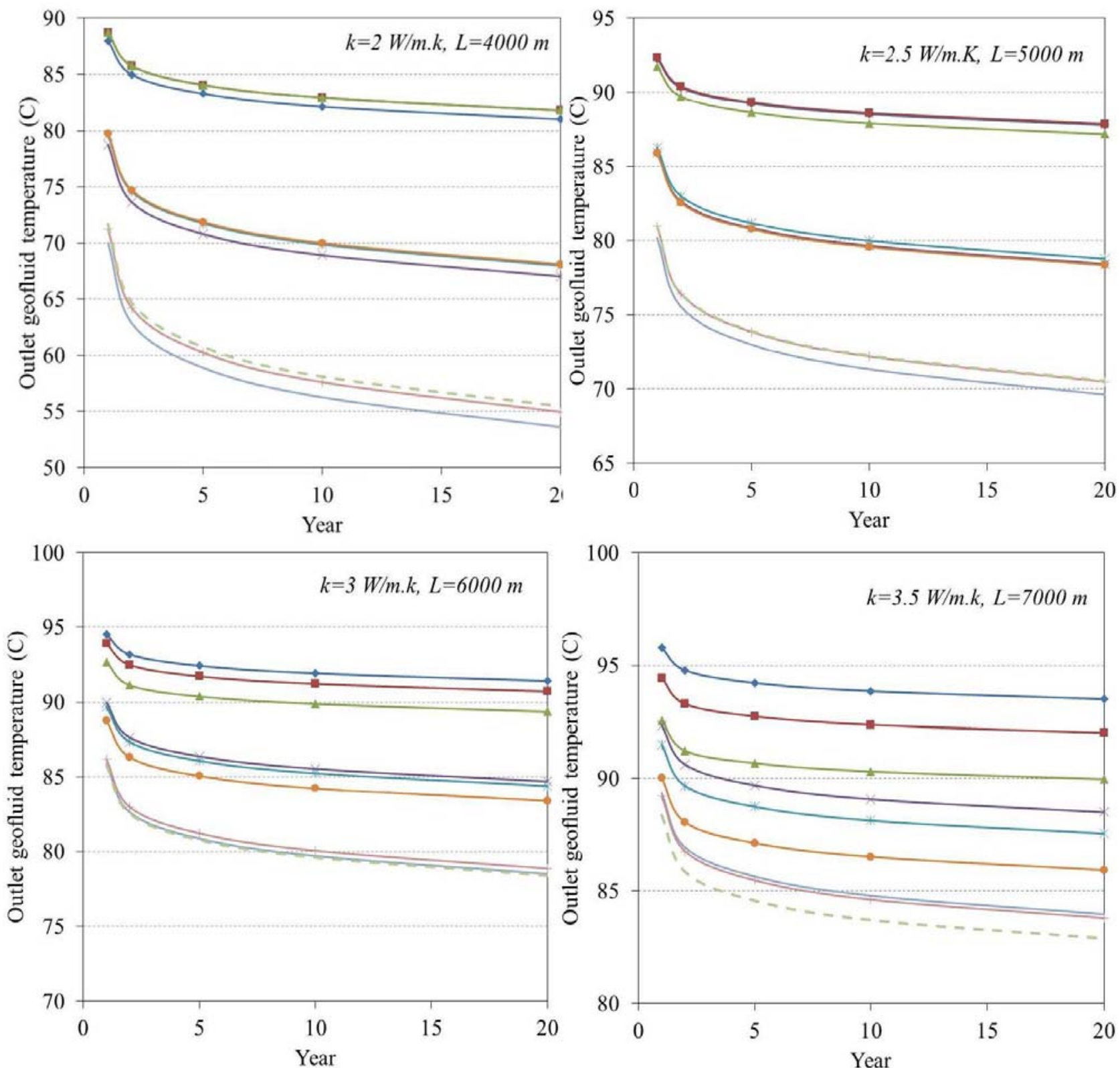

$-P=350 \mathrm{~kW}, D T=10 \mathrm{C} \longrightarrow P=250 \mathrm{~kW}, D T=10 \mathrm{C}-P=350 \mathrm{~kW}, D T=16 \mathrm{C}$

$\rightarrow P=150 \mathrm{~kW}, D T=10 \mathrm{C}-P=250 \mathrm{~kW}, D T=16 \mathrm{C}--P=350 \mathrm{~kW}, D T=20 \mathrm{C}$

$\rightarrow P=250 \mathrm{~kW}, D T=20 \mathrm{C} \rightarrow-P=150 \mathrm{~kW}, D T=16 \mathrm{C} \rightarrow P=150 \mathrm{~kW}, D T=20 \mathrm{C}$

Fig. 2 Temperature of geofluid extracted for a petroleum well along with the time for different operating conditions. 

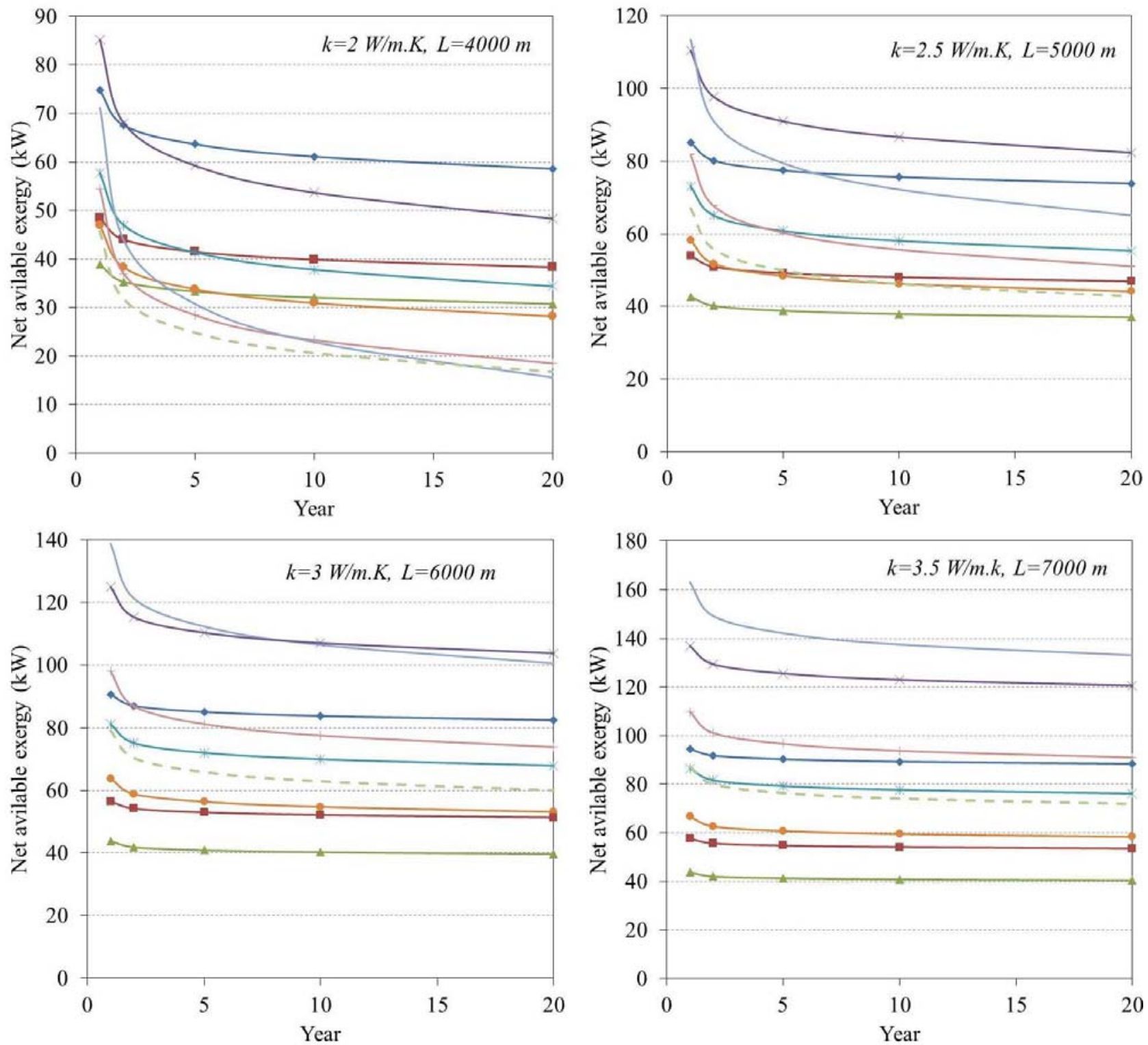

$-P=350 \mathrm{~kW}, D T=10 \mathrm{C}-P=250 \mathrm{~kW}, D T=10 \mathrm{C}-P=350 \mathrm{~kW}, D T=16 \mathrm{C}$

$\rightarrow-P=150 \mathrm{~kW}, D T=10 \mathrm{C} \rightarrow P=250 \mathrm{~kW}, D T=16 \mathrm{C}--P=350 \mathrm{~kW}, D T=20 \mathrm{C}$

$\rightarrow P=250 \mathrm{~kW}, D T=20 \mathrm{C} \rightarrow-P=150 \mathrm{~kW}, D T=16 \mathrm{C} \rightarrow-P=150 \mathrm{~kW}, D T=20 \mathrm{C}$

Fig. 3 Net available exergy at petroleum well along with the time for different working parameters. 


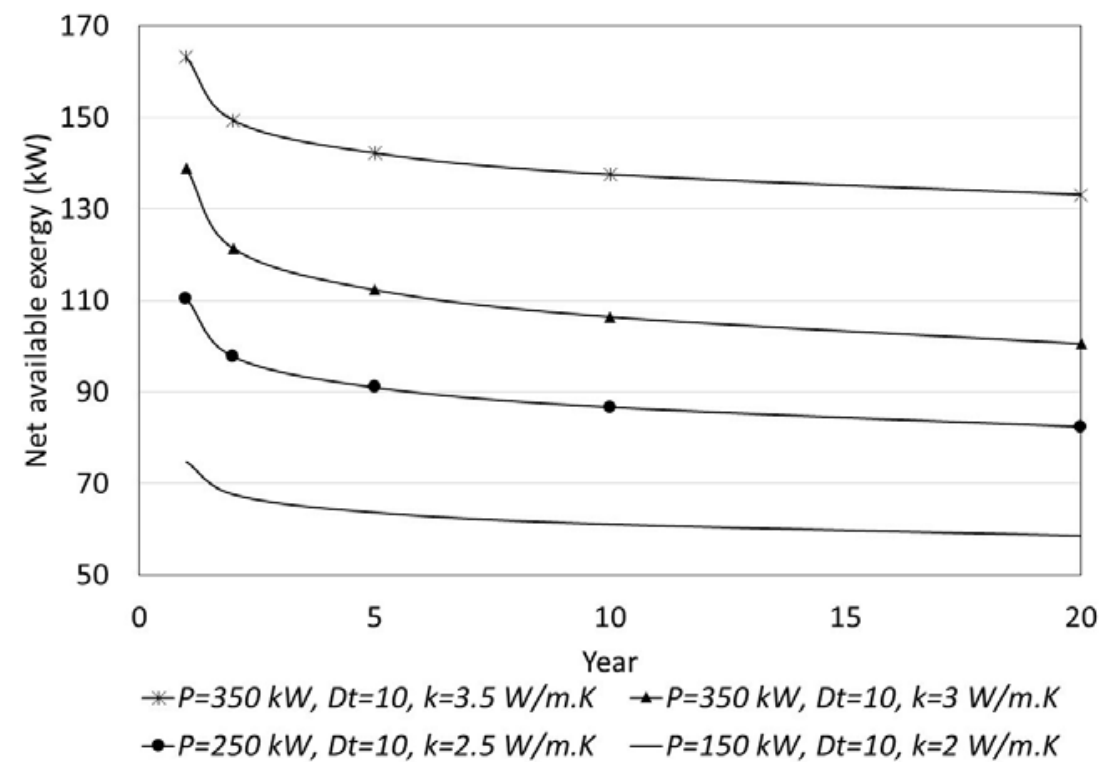

Fig. 4 The optimized available exergy along with the time for different ground thermal conductivity and operation conditions.

that is not acceptable for electricity generation. Obviously, as the extraction rate increases the geofluid outlet temperature decreases. The simulations show that the effect of the temperature difference $\Delta \mathrm{T}$ between inlet and outlet of the well on geofluid outlet temperature is insignificant. In contrast, $\Delta \mathrm{T}$ has an apparent impact on the energy availability of the geothermal resource. The higher $\Delta \mathrm{T}$, the lower energy availability of the well will be.

The thermal conductivity of the rock mass dictates how quickly the geothermal resource undergoes heat regeneration. Therefore, it is advantageous to seek resources with a higher thermal conductivity. Finally, in the current study, a computer model is developed based on a combination between two well-known softwares. The model can be used to optimize the designing parameters of a geothermal resource for any sites and conditions of interest.

\section{Acknowledgement}

This work was made possible by an NPRP 7-725-2-270 a grant from the Qatar National Research Fund (a member of The Qatar Foundation). The statements made herein are solely the responsibility of the authors.

\section{References}

[1] Bu, X., Ma, W., and Li, H., 2012. "Geothermal Energy Production Utilizing Abandoned Oil and Gas Wells." Renewable Energy 41: 80-5.

[2] Esen, M., and Yuksel, T. 2013. "Experimental Evaluation of Using Various Renewable Energy Sources for Heating a Greenhouse." Energy and Buildings 65: 340-51.

[3] Balbay, A., and Esen, M. 2010. "Experimental Investigation of Using Ground Source Heat Pump System for Snow Melting on Pavements and Bridge Decks." Scientific Research and Essays 5: 3955-66.

[4] Esen, H., Inalli, M., and Esen, M. 2007. "Numerical and Experimental Analysis of a Horizontal Ground-Coupled Heat Pump System.” Building and Environment 42: 1126-34.

[5] Lund, J. W. 2006. "Hot Springs, Power and Ice." Geo-Heat Center Quarterly Bulletin 27: 2.

[6] EIA. 2012. "Petroleum and Other Liquids." U.S Energy Information Administration Vol. 2015, No. January.

[7] Templeton, J. D., Ghoreishi-Madiseh, S. A., and Hassani, F. 2014. "Abandoned Petroleum Wells as Sustainable Sources of Geothermal Energy." Energy 70: 366-73.

[8] Kharseh, M., Al-Khawaja, M., and Hassani, F. 2015. "Utilization of Oil Wells for Electricity Generation: Performance and Economics.” Energy 90, Part 1: 910-6.

[9] Lund, J. W., Freeston, D. H., and Boyd, T. L. 2010. "Direct Utilization of Geothermal Energy 2010 Worldwide Review." Anonymous 1-23.

[10] Wei, Y., Wang, F., and Ren, B. 2009. "Drainage and Production by Using Geothermal in Huabei Oil Region." Oil Drilling \& Production Technology 31: 93-5. 
[11] Kurevija, T., and Vulin, D. 2011. "High Enthalpy Geothermal Potential of the Deep Gas Fields in Central Drava Basin, Croatia." Water Resources Management 25: 3041-52.

[12] Kujbus, A. 2007. "New Approach in the Hungarian Geothermal Exploration." Geothermal Resources Council Transactions 31: 605-7.

[13] Reyes, A. G. 2007. "Abandoned Oil and Gas Wells: A Reconnaissance Study of an Unconventional Geothermal Resource."

[14] Barbacki, A. 2000. "The Use of Abandoned Oil and Gas Wells in Poland for Recovering Geothermal Heat." In Proceedings of World Geothermal Congress, 3361-5.

[15] Limpasurat, A., Falcone, G., and Teodoriu, C. 2011. "Artificial Geothermal Energy Potential of Steam-Flooded Heavy Oil Reservoirs." International Journal of Oil, Gas and Coal Technology 4: 31-46.

[16] Sanyal, S. K., and Butler, S. J. 2010. "Geothermal Power Capacity from Petroleum Wells-Some Case Histories of Assessment." In Proceedings of World Geothermal Congress 2010, Anonymous.

[17] Davis, A. P., and Michaelides, E. E. 2009. "Geothermal Power Production from Abandoned Oil Wells." Energy 34: 866-72.

[18] Kujawa, T., Nowak, W., and Stachel, A. A. 2005. "Analysis of the Exploitation of Existing Deep Production Wells for Acquiring Geothermal Energy." Journal of Engineering Physics and Thermophysics 78: 127-35.

[19] Al-Khoury, R., and Bonnier, P. 2006. "Efficient Finite Element Formulation for Geothermal Heating Systems.
Part II: Transient.” International Journal for Numerical Methods in Engineering 67: 725-45.

[20] Wang, Z., McClure, M. W., and Horne, R. N. 2010. "Modeling Study of Single-Well EGS Configurations." Presented at the World Geothermal Congress, Bali, Indonesia.

[21] Garbai, L., and Méhes, S. 2011. "Energy Analysis of Geothermal Heat Pumps with U-tube Installations." Exploitation of Renewable Energy Sources (EXPRES), 2011 IEEE 3rd International Symposium on, Anonymous IEEE, 107-12.

[22] Li, Z., and Zheng, M. 2009. "Development of a Numerical Model for the Simulation of Vertical U-Tube Ground Heat Exchangers." Applied Thermal Engineering 29: 920-4.

[23] Dittus, F., and Boelter, L. 1985. "Heat Transfer in Automobile Radiators of the Tubular Type." International Communications in Heat and Mass Transfer 12: 3-22.

[24] Adamson, K., Birch, G., and Gao, E. 1993. "High-Pressure, High-Temperature Well Construction." Oilfield Review 5: 15-32.

[25] RasGas. 2013. "Direct Contact with Eng. Nasser Elfayoumi."

[26] Kharseh, M. 2011. "Reduction of Prime Energy Consumption by Ground Source Heat Pumps in a Warmer World." Ph.D. thesis, Luleå University of Technology.

[27] Banks, D. 2015. "A Review of the Importance of Regional Groundwater Advection for Ground Heat Exchange." Environmental Earth Sciences 73: 2555-65. 